\title{
PESQUISA PSICANALÍTICA SOBRE OS FENÔMENOS PSICOSSOMÁTICOS
}

Yorgos Dimitriadis

\author{
Yorgos Dimitriadis \\ Psiquiatra, \\ psicanalista. \\ Ex-psiquiatra \\ hospitalar. Professor \\ da Unidade de \\ Formação e \\ Pesquisa (UFR) \\ em estudos \\ psicanalíticos do \\ Laboratório do \\ Centro de Pesquisas \\ em Psicanálise, \\ Medicina e \\ Sociedade (CRPMS) \\ da Universidade \\ Paris-Diderot
}

Tradução

Fabiana Campos Baptista

Doutora em

Psicopatologia

e Psicanálise

(Universidade Paris

Diderot Sorbonne

Cité). Mestre

em Psicanálise

(Universidade

Paris 8). Mestre

em psicologia

(UFMG). Professora

adjunta do Centro

Universitário de

Belo Horizonte

(UNI BH).
RESUMO: Lacan abordou os fenômenos psicossomáticos através do conceito de significante congelado. Os autores que se inspiraram nele fizeram uso desse conceito de diversas maneiras. Existem diferenças entre esses autores quanto à possibilidade de uma determinação concreta de tais significantes congelados (holófrases) que seriam suscetíveis de serem enfatizados pelo analista. Segundo alguns desses autores, o enfatizar tais significantes poderia colocar fim aos fenômenos psicossomáticos. Outros autores lacanianos contestam o valor clínico desse tipo de intervenção. O autor questiona também o parentesco entre os fenômenos psicossomáticos e outros fenômenos clínicos como a alucinação, a emoção, o humor e a passagem ao ato. Palavras-chave: Ato, afeto, embaraço, holófrase, psicossomático.

ABSTRACT: Psychoanalytic research on psychosomatic phenomena. Lacan approached the psychosomatic phenomena using the concept of the frozen signifier. Lacanian authors have used this concept in a variety of ways. Yet differences do exist among Lacanian writers themselves, mainly in what concerns the possibility of a concrete determination of such frozen signifiers (holophrasis), which could be spotted by the therapist. According to some of these authors, emphasizing such signifiers could lead the psychosomatic phenomena to an end. Other Lacanian writers question the clinical value of this type of intervention. The author also questions the kinship between the psychosomatic phenomena and other clinical phenomena such as hallucination, emotion, mood and passing in the action.

Keywords: Act, affect, embarrassment, holophrasis, psychosomatic.

DOI - http://dx.doi.org/10.1590/S1516-14982016000100003 


\section{INTRODUÇÃOO}

Hoje, existe uma tendência, nas pesquisas relativas aos fenômenos psicossomáticos, a um distanciamento do "discurso psicanalítico". Isto se passaria segundo diversas modalidades, às quais vamos mencionar apenas algumas:

1. Para P. Marty, M. de M’Uzan, e outros autores (MARTY, 1990), do instituto psicanalítico de Paris, existe, nos pacientes que apresentam fenômenos psicossomáticos, carência de processos pré-conscientes, fantasmáticos, de sentido, de relações objetais e de simbolização. É pelo termo "pensamento operatório" que esta carência foi qualificada por estes dois autores. Sua concepção, que vai no sentido negativo, assim como o título de "especialista em psicossomática" - pelo qual este instituto valida o curso de seus membros - corre o risco de consagrar ainda mais a "psicossomática" como disciplina e, daí, torná-la independente da psicanálise.

2. O termo neológico 'alexitimia’ foi introduzido, de acordo com J.-L. Pedinelle e G. Rouan (PEDINELLI \& ROUAN, 1998), pelos americanos P.E. Sifneos e J.C. Nemiah, para se referir a pacientes cujo quadro clínico se caracteriza por uma dificuldade em verbalizar os sentimentos e as emoções, uma capacidade fraca de empatia, uma labilidade emocional, um discurso factual e pragmático, evitando toda implicação afetiva. Os pacientes sofrendo de afecções psicossomáticas teriam, segundo estes autores, um problema fixo (eventualmente um déficit neurológico) que impediria esse tipo de operações psíquicas. Segundo Pedinelli e Rouan (idem), o tratamento psicanalítico seria, para Sifneos, ineficaz ou poderia agravar os transtornos.

3. Para os clínicos que se inspiram no ensino de Jacques Lacan, também existem controvérsias em torno da atitude que o analista deveria ter quando os fenômenos psicossomáticos se apresentam durante a cura, sobretudo no que concerne às possíveis intervenções sobre a chamada holófrase. Pensamos que o risco do distanciamento do discurso analítico também se coloca aqui; pois as intervenções que ocorrem dos pretendidos significantes congelados, que nenhum dentre eles preconizam, não dependeriam mais de uma atitude de domínio da parte do clínico, confrontado com formações em relação às quais os sujeitos em questão pareciam não estar divididos? Outros autores, que se inspiram em Lacan, insistem no parentesco dos fenômenos psicossomáticos com outros fenômenos clínicos, como a "passagem ao ato", e preconizam uma atitude moderada face a esses fenômenos durante a cura, em que a interpretação se aplicaria somente às formações que assinalam a divisão subjetiva. Em seguida, vamos discutir essa controvérsia na literatura lacaniana, começando pelo que o próprio Lacan avançou sobre estas questões difíceis da clínica. 


\section{JACQUES LACAN SOBRE OS FENÔMENOS PSICOSSOMÁTICOS}

É no segundo seminário de Jacques Lacan que encontramos uma primeira referência ${ }^{1}$ aos fenômenos psicossomáticos, quando Lacan intervêm em um debate entre F.Perrier e J.-P.Valabrega, autor de um livro (VALABREGA, 1966) sobre as teorias psicossomáticas, que acabava de ser lançado.

Vale lembrar que Valabrega (1966) considerava o fenômeno psicossomático a partir de uma generalização do conceito de conversão pelo viés de seu conceito de "recalque psicossomático" e de “fantasma”. Em princípio, Lacan (19531954/1978) diz, em seu seminário, que reina sobre a psicossomática uma grande confusão. Em seguida, ele situa os fenômenos psicossomáticos para além das construções neuróticas, em que o narcisismo é uma linha divisória. Por trás do narcisismo, há o autoerotismo e os investimentos propriamente intraorgânicos que, segundo ele, chamamos em análise de autoeróticos e que exercem com certeza um papel muito importante nos fenômenos psicossomáticos. Não é uma relação ao objeto.

Quando existem investimentos chamados autoeróticos, não podemos distinguir a fonte do objeto. Nas neuroses, sempre existem, é claro, os mecanismos de defesa que estão sempre ligados à relação narcísica, no que ela é estritamente estruturada pela identificação possível ao outro. A neurose é sempre enquadrada pela estrutura narcísica. As relações psicossomáticas, ao contrário, estão no nível do real e devem ser compreendidas aqui como sendo o rochedo do biológico (e não como o impossível, que é uma conceituação posterior de Lacan sobre o real). Como nota Patrick Valas (1986), logo que Lacan acrescenta que não se pode distinguir a fonte do objeto, temos aqui a indicação, que continuará central, de uma espécie de curto-circuito na montagem pulsional.

Encontramos uma segunda referência importante de Lacan sobre a psicossomática em seu terceiro seminário (LACAN, 1955-1956/1981) quando ele comenta um trabalho de Ida Macalpine sobre uma psicose, que ela evoca os sintomas hipocondríacos. Encontra-se aqui, diz Lacan (1955-1956/1981, p.352), logo à primeira vista, alguma coisa de particular que está no âmago da relação psicótica, como os fenômenos psicossomáticos. É neste momento que Macalpine

"pôde ter a apreensão direta de fenômenos estruturados de modo bem diferente do que se passa nas neuroses, a saber, onde há não sei que impressão ou inscrição direta de uma característica, e mesmo, em certos casos, de um conflito, no que se pode chamar o quadro material que apresenta o sujeito enquanto ser corpóreo." (LACAN, 1955-1956/1981, p.352)

\footnotetext{
${ }^{1}$ Existe de fato uma referência anterior (LACAN et al., 1953) sobre a hipertensão arterial.
} 
Vemos aqui as premissas da ideia que Lacan (1955-1956/1981) vai evocar bem mais tarde, da relação do fenômeno psicossomático com o símbolo (impressão ou inscrição), e até mesmo com o número:

"uma erupção, diversamente qualificada dermatologicamente, da face, se mobilizará em função de tal aniversário, por exemplo, de maneira direta, sem intermediário e sem dialética alguma, sem que nenhuma interpretação possa marcar sua correspondência com algo coisa que seja do passado do sujeito." (idem, p.352)

Então, vemos aqui Lacan, de um lado, aproximar o fenômeno psicossomático da hipocondria psicótica e, por outro lado, distingui-la do sintoma neurótico que é dialetizável pelo sujeito e é um intermediário, pois ele constitui um modo de endereçamento ao Outro. Nos fenômenos psicossomáticos, porém, o corpo "como Outro" revela o golpe de um conflito. Há uma correspondência direta, neste caso, com o símbolo, que é diferente do significante. Mas ele precisa que (LACAN, 1955-1956/1981) é sem dúvida isto que levou Ida Macalpine a se colocar o problema muito singular das correspondências diretas entre o símbolo e o sintoma.

A terceira referência de Lacan, desta vez mais importante, encontra-se no seminário XI (LACAN, 1964/1973, p.206): “A psicossomática é alguma coisa que não é um significante, mas que ainda assim só é concebível na medida em que a indução significante, no nível do sujeito, se passou de uma forma que não coloca em jogo a afânise do sujeito." Lacan avança isso em um contexto no qual ele acabava de desenvolver as operações de realização do sujeito no lugar do Outro em sua dependência significante, através de duas operações lógicas: a alienação e a separação.

Um pouco mais adiante, no seminário, Lacan (1964/1973, p.210) afirma que:

"é na medida em que uma necessidade viria a se interessar pela função do desejo que a psicossomática pode ser concebida [...] o elo do desejo é aqui conservado, mesmo se não podemos mais dar conta da função de afânise do sujeito." (LACAN, 1964/1973, p.210)

E, em seguida, ele tenta explicar isso pelo reflexo condicionado de Pavlov, pois, no reflexo, está implicada uma necessidade, a do cachorro que saliva quando ele escuta o sinal. Isto é, produzindo no animal um estímulo não adequado à necessidade (a campainha, por exemplo, no lugar do pedaço de carne), mas que interessa a uma necessidade, introduzimos um elemento heterogêneo na organização dessa necessidade, um corte do desejo do Outro, que é, neste caso, o do experimentador. 
A experiência pode provocar no animal todo tipo de desordem, mas não sendo até o momento presente um ser falante, ele não é chamado a colocar em questão o desejo do experimentador. Lacan (1964/1973, p.215) afirma ainda no seminário XI: "Eu formularia até que, quando não há intervalo entre S1 e S2, quando a primeira dupla de significantes se solidifica, se holofraseia, temos o modelo de toda uma série de casos ainda que, em cada um, o sujeito não ocupe o mesmo lugar”. Essa série de casos diz respeito, além dos fenômenos psicossomáticos, à debilidade e à paranoia, como veremos um pouco mais adiante.

É a primeira vez que Lacan avança a ideia de uma solidificação da cadeia significante (uma massificação da cadeia, que se tornará também significante “congelado", em sua conferência em Genebra) e o termo holófrase, que conhecerá, como veremos mais adiante, múltiplas leituras pelos seus sucessores. Mas vamos, primeiramente, resumir a aproximação que Lacan faz entre o fenômeno psicossomático e o reflexo condicionado. Quando existe uma massificação da cadeia significante, a dialética do desejo estaciona se interrompe/para e "o significante do desejo do Outro" obtêm — por causa disso — uma opacidade, ele torna-se misterioso. Neste estado, ele para de reenviar a um outro significante para se tornar um indutor, um sinal, que induz as perturbações das necessidades do soma, ao invés de relançar a dialética do desejo do sujeito.

Isso significa que haveria uma analogia entre o significante congelado e o sinal do experimentador da experiência de Pavlov (da campainha no lugar da carne) quando ele tentava condicionar o animal domesticado (e, como tal, sensível aos sinais vindos de outro humano), a saber, o cachorro. Para além do fenômeno psicossomático, Lacan (1964/1973) inclui na mesma série (ainda que ele precise que o sujeito não ocupe o mesmo lugar) a criança débil: "na medida em que entra a dimensão psicótica em sua educação, isto é, na medida em que a mãe a reduz a ser apenas o suporte de seu desejo em um termo obscuro”. Depois, na mesma série, ele fala da crença na psicose:

“[A psicose] é o que proíbe a abertura dialética que se manifesta no fenômeno da crença. No fundo da própria paranoia, que nos parece porém animada de crença, reina esse fenômeno de Unglauben. Não é não crer nisso, mas a ausência de um dos termos da crença, do termo em que designa a divisão do sujeito.” (LACAN, 1964/1973, p.215)

Poderíamos acrescentar que "crer” implica uma divisão fundamental, uma aposta no Outro, um investimento libidinal da alteridade do outro. Segundo Lacan, é isso que faz a diferença entre neurose e psicose "Na psicose, as vozes, o sujeito não só acredita (il y croit), mas acredita nelas (il les croit)", dirá em 1975 (LACAN, 1975). 
A última referência de Lacan à psicossomática se encontra em uma conferência sobre o sintoma, dada em Genebra (LACAN, 1975/1985). Em resposta a uma questão colocada pelo auditório sobre a natureza dos fenômenos psicossomáticos, ele respondeu:

“é certo que este é um domínio muito pouco explorado. Enfim, é algo da ordem do escrito. Em muitos casos não sabemos lê-lo. Precisaria dizer aqui algo coisa que introduza a função do escrito. Tudo se passa como se algo estivesse escrito no corpo, como coisa que se oferece como enigma. Não é surpreendente que tenhamos este sentimento como analistas." (LACAN, 1975/1985, p.10)

Em seguida, à questão da mesma pessoa: "Mas como fazê-los falar daquilo que está escrito? Aqui, me parece que há um corte”, ele respondeu: “é verdade. Existe isto que os místicos chamam de assinatura das coisas, o que existe nas coisas que se pode ler. Signatura não quer dizer signum, não é mesmo? Existe algo para se ler, diante do qual, muitas vezes, boiamos”.

Quanto à questão do Doutor Nicos Nicolaides, membro do Instituto de Psicossomática de Paris, e bem mais tarde, autor de uma obra sobre a representação (NICOLAIDIS, 1993), se a psicossomática se exprime com uma linguagem de hieróglifo, enquanto o neurótico se exprime com uma linguagem alfabética, Lacan respondeu que "sim, o corpo considerado como um cartucho liberando o nome próprio”, precisando mais adiante que este hieróglifo "não seria provavelmente um grito”. Ele precisa que é em torno do traço unário, termo com o qual ele havia traduzido o einziger Zug de Freud, que gira toda a questão do escrito. “E o corpo no significante faz traço, traço que é um UM”. Por fim, ele interroga a questão do gozo presente na psicossomática. Ele retoma a metáfora do "congelado", dizendo que se ele a escolheu, é porque existe certamente uma espécie de fixação: "Não é à toa também que Freud emprega o termo Fixierung é porque o corpo se deixa escrever algo da ordem do número". E mais adiante, na mesma conferência, ele propõe uma modalidade de aproximação do fenômeno psicossomático na cura: "é pela revelação do gozo específico que há na sua fixação, que sempre é preciso abordar o psicossomático [...]. É na medida em que, o que se espera, é dar-lhe o sentido do que se trata. O psicossomático é algo que é, ainda assim, em seu fundamento, profundamente arraigado no imaginário”. Vemos então que Lacan aproxima o fenômeno psicossomático de uma escrita enigmática, para a qual ele emprega os termos de configuração, de traço, de assinatura e de hieróglifo, escrita então mais imaginária e que fixa um gozo específico. Em seguida, muitos autores insistiram no caráter “de imitação” do fenômeno psicossomático. 


\section{FENÔMENOS PSICOSSOMÁTICOS E HOLÓFRASE}

Jean Guir escreveu numerosos artigos sobre os fenômenos psicossomáticos e um livro (GUIR, 1984) intitulado Psicossomática e câncer. Neste livro, que é de fato um apanhado de artigos, o autor retoma um fragmento da análise de um paciente sofrendo de enxaqueca, para quem a interpretação "Onde está o mistério" desenlaça, "descongela” a holófrase "Westminster — Winchester", que surge "perto do umbigo de um sonho", e faz desaparecer as enxaquecas. Guir diferencia o fenômeno psicossomático do fenômeno psicótico, pelo fato de que o elo do desejo seria conservado nos primeiros, enquanto isto não seria o caso nos segundos. Até porque o Outro goza do órgão no primeiro, enquanto ele goza do corpo inteiro nos psicóticos. Para este mesmo autor, nesses pacientes, a metáfora paterna funciona em certos lugares do discurso e não em outros. Apenas determinados momentos específicos do discurso provocam um desencadeamento no corpo. Pode-se perguntar, ele diz, se "o transtorno corporal, acontecimento do corpo, não viria atuar como um dos Nomes-do-Pai”.

Monique Liart (1992, p.18), em referência a Jacques-Alain Miller (1986) e também aos trabalhos de Guir, sustenta que a atitude do psicanalista - em relação aos doentes psicossomáticos — deve se pautar em função da estrutura da pessoa. Na neurose:

"há um golpe localizado na metáfora subjetiva. Se existe, em relação a um signi-
ficante, imobilidade e impossibilidade de retorno do S2 sobre o S1, isso não im-
pede que o elo do desejo seja conservado. Quanto a um significante que se refere
à identificação primordial, o Outro é contornado. O Outro torna-se o corpo [...].
A interpretação do analista deve visar então à restabelecer, em relação a este signi-
ficante congelado, a significação fálica. Esta interpretação não pode ser do registro
da metátora, já que o S2 não existe. Ela deve ser uma injunção significante: trata-se
de injetar o significante faltante para transformar o FPS em sintoma [...], dar-lhe o
sentido concernente." (LIART 1992, p.66)

Assim, ela traz (LIART, 2000, p.18-19) o caso de uma mulher histérica a quem seu pai havia dito: "Você é a menina dos meus olhos", 2 "Você não vai se casar, você vai ficar comigo”. Estas palavras, esses S1, teriam traçado o destino desta mulher como solteira e, em seguida, como menina (prunelle) cegada pelas lágrimas. Seu fenômeno psicossomático teria inscrito em seu corpo o glauco-homem, holófrase de uma cena: uma menininha que vê seu pai pela última vez, antes que ele parta para o campo de concentração, com o olhar banhado de lágrimas.

\footnotetext{
${ }^{2}$ No original: “Tu es la prunelle de mes yeux". Em francês, a palavra prunelle significa pupila.
} 
Liart nota que, neste momento, não existe mais diferença entre sua pupila (prunelle) e a de seu pai, pois os dois se olhavam mas não se viam.

"A esquize do olho e do olhar produz aqui este objeto a, onde o corpo se mostra como falha, isto é, como dejeto. O pai havia sido elevado pela menina ao ranque de um grande ideal. Suas palavras funcionaram como traços unários decidindo implacavelmente seu destino.” (LIART, 2000, p.19)

Vimos que a autora propõe para esta paciente neurótica a injunção significante "glauco-homem". No mesmo artigo, ela sustenta que a interpretação do analista deve visar uma perda do gozo específico do fenômeno psicossomático, que está ligado, na maioria das vezes, a um ser amado. Por outro lado, na cura do psicótico, diz ela (LIART, 1989), ao contrário do tratamento do FPS na neurose, não se trata de fazer a injunção significante. Para a autora, o FPS, nesses casos, deveria ser mantido como insígnia do sujeito (termo que ela retoma de Miller): ele serve de suplência e permite fazer passar o gozo à uma contabilidade, e então ele não deve ser interpretado, mas preservado.

Patrick Monribot (2007) traz o caso de um homem que, com cerca de 3 anos, surpreendeu uma cena que ficou gravada como uma lembrança encobridora:

"Pela fresta da porta, ele percebe sua mãe ajoelhada e concentrada, cuidando do pênis machucado do pai, que está assentado, entregue às mãos maternas. Ela segura um frasco de mercúrio-cromo com o qual pincela o órgão do pai, órgão que se torna simplesmente uma mancha avermelhada.” (MONRIBOT (2007, p.5)

$\mathrm{Na}$ idade de 11 anos, ele contraiu um tique (que consistia em arregalar os olhos), quando assistiu à outra cena na qual seu pai furou o olho cortando madeira. Quatro anos mais tarde, sua primeira relação sexual é marcante, pois provocou ao mesmo tempo a cura do tique, mas também o desencadeamento de uma rinite que persistiu em seguida. Na idade adulta, ele começou uma cura analítica e, dez anos depois, o analisante tornou-se pai. Monribot (2007) comenta que neste momento crítico da cura:

"O evento teria orientado o trabalho analítico em direção a esta complicada questão: o pai que ele vai ser, este que ele teve, teria querido ter, etc. [...]. Pouco a pouco, reaparece no divã, e sempre em relação ao pai, a cena primitiva [...] muitas significações e sentidos: sexual, edipiano. Mas há, porém, um ponto estranho, heterogêneo nesta história, que continua decididamente fora de sentido: o mercúrio-cromo que produz uma mancha na cena, mancha que, é o caso de dizer, cativa a criança. [...]. Este ponto enigmático permite ao analista de ressaltar e de sair do silêncio para 
fazer valer o estatuto de holófrase deste significante. Ele vai decompor lentamente a palavra que faz mancha: 'mãe-cura-ocre-homem' (mère-cure-ocre-homme)." (MONRIBOT, 2007, p.6)

Esta intervenção do analista teria feito desaparecer a rinite, mas para fazer reaparecer o tique que ele tinha antes. Porém, Monribot (2007, p.9) não deixa de sublinhar que existe certa contingência neste caso: "Isto poderia não ter aparecido no material da cura. Nos tratamentos, é raro conseguir isolar tal significante, tal bloco tendo um valor holofrásico.” Mas em nenhum momento, diz o autor (MONRIBOT, 2007, p.8), "ele colocou em questão a sua rinite, pois não foi isto que o levou para a análise. E, se ele conseguiu curar a rinite no tratamento, foi por um simples efeito colateral”.

\section{FENÔMENOS PSICOSSOMÁTICOS E GOZO}

Entretanto, muitos autores, como veremos, propõem uma atitude menos direta - que a injunção significante - em relação aos fenômenos psicossomáticos. Por exemplo, na introdução de um número da revista $O$ trimestre psicanalítico (Le trimestre psychanalytique) sobre a psicossomática (1988), lemos:

“Diferentemente das construções neuróticas, cujo sentido é o de mascarar esta verdade, em que o que faz falar se orienta por uma perda, contrariamente aos fenômenos psicóticos que a desmascaram sem levar em conta o sujeito, aqui, algum UM inscrito mostra, mas não se articula: o desaparecimento do fenômeno na cura assinala antes uma troca de gozo do que um efeito da interpretação (a despeito da literatura).” (1988, p.9)

A "literatura” se refere provavelmente aos casos em que uma injunção significante (ou desfragmentação de uma holófrase, segundo uma expressão de Monribot) teria feito ceder o fenômeno psicossomático. De acordo com esse mesmo editorial, temos nos fenômenos psicossomáticos "um imaginário tomado em contato direto com o real e desconectado do simbólico fálico que daria a ele a dimensão do sentido" e cuja revelação deveria ser visada pelo ato analítico. Este mesmo editorial faz uma distinção clara entre conversão histérica e fenômenos psicossomáticos que:

“[...] atinge pacientes presos em uma conjetura simbólica que se distingue da posição histérica. O sintoma histérico se apresenta, com efeito, como um traço de identificação do sujeito, retorno do recalcado através do qual o desejo inconsciente se significa. A interpretação pode restituir a mensagem do sujeito, contanto que 
ele esteja no ponto de assumir o seu custo [...] é por isso que se falará de fenômeno mais do que de sintoma, as manifestações psicossomáticas se apresentam ao paciente como não o concernindo, na qualidade de um desejo [...]. Não significa que o paciente não tenha reparado nas coincidências do desencadeamento, mas isso não abre, necessariamente, espaço para fazer apelo a configuração de um sentido, apelo esse que permitiria as condições de uma transferência que é, nesse caso, sempre problemática." (idem)

Charles Melman (1988), neste mesmo número da revista, assinala que uma afecção psicossomática como o torcicolo espasmódico ocorreu em três de seus pacientes, no momento em que se tratava de uma ultrapassagem, seja de sua atividade profissional, seja de caráter incestuoso, ou mesmo os dois ao mesmo tempo. Aqui, existem fatores "limiares”, isto é, uma simbolização, se poderia dizer, muito próxima do imaginário. Este autor avança assim com muito mais prudência que outros, sobre a possibilidade de localizar um significante qualquer “congelado", ainda que ele dê um exemplo disso, como veremos adiante, sobre o imaginário da letra.

Para esse mesmo autor, nas doenças psicossomáticas, não seria tanto o corpo que gozaria dele mesmo, o órgão é que viria a gozar dele mesmo. Melman diz ainda, falando da relação da mãe com sua criança asmática, que não existe entre elas nenhuma zona obscura, dito de outro modo, que a junção de suas superfícies é perfeita e que estas mães, em geral, experimentam um gosto particular pela limpeza de todas as fendas e orifícios: é preciso que ele seja expurgado de tudo o que poderia vir a se alojar ali.

Ele deduz então que se pode de modo intuitivo compreender que tal exigência amorosa vem obstruir o que, entre os significantes, é o lugar do que podemos legitimamente chamar o spiritus. O autor dá, em seguida, o exemplo de um caso clínico em que a letra " $R$ " tem um papel. Ele se inscreve na palavra alemã HERR (que significa "senhor" e é uma homofonia com a palavra francesa "air" (ar) e a letra R). Vindo para a França com 3 anos, ele se viu exposto a dificuldades respiratórias. Seria o imaginário da letra (tão importante na criança) — aqui da letra "R" - que teria vindo de alguma maneira costurar os significantes, quando ele foi de Rhin ao país gaulês.

Jean-Piere Lebrun (2006) acredita que existem sujeitos que usam de sua potencialidade psicossomática para obturar, o mais rápido possível, a abertura, avistada de relance, entre S1 e S2 e impedir, deste fato, a possível inscrição da perda. Tal formulação, diz ele:

“poderia evidentemente fazer crer que se trata de uma decisão que foi refletida pelo sujeito. Evidentemente, não é o caso. [...]. Isto acontece em um momento em que a 
relação com o Outro ainda não está instituída, em que a separação do Outro ainda não aconteceu. Trata-se então de uma forma de não pagar o preço do impossível, já que este último é perfeitamente inscrito [...]. Então, através desse mecanismo de holófrase, tudo se passa como se o sujeito permanecesse em um indecidível, em uma recusa a consentir em entrar no registro da perda. E, assim, bloqueando o processo implicado pela indução significante, tudo se passa como se o sujeito deixasse ao seu organismo o cuidado de resolver essa questão.” (LEBRUN, 2006, p.161)

Para Valas (2009), o movimento de subjetivação de uma lesão psicossomática, inicia-se no tratamento a partir do momento em que, na maioria das vezes sem o seu conhecimento, o analisante fala de sua lesão nos mesmos termos de sua angústia e, muitas vezes, em alternância com ela. "Não sendo um sintoma, não se trata aqui de manejar o equívoco significante jogando com sua parte de non-sens para reduzi-lo. [...]. Seguindo as indicações de Lacan, como a lesão é "não-a-ler" (pas-à-lire), porque é um escrito indecifrável, é conveniente temporizar e situar a intervenção em outro lugar, para poder dar sentido ao seu gozo”.

Ele propõe:

“[...] deixar o sujeito dizer, deixar ir de maneira refletida o livre jogo de sua angústia, de modo que possa se produzir um distanciamento, uma flutuação, onde o sujeito terá a oportunidade de sair desse ponto de petrificação, de congelamento, fixado que está no gozo específico de sua lesão. Pouco a pouco, ela vai ganhar sentido para ele. Não é certo, porém, que quando ocorre uma remissão, ela seja obtida graças a uma intervenção precisa referente a um significante causal, mesmo supondo que se possa determiná-lo. [...]. Em caso de remissão da lesão, a questão que se coloca sempre é saber se ela foi obtida a partir de uma simbolização conseguida em um relance do processo de subjetivação, ou se ao contrário, ela é somente o resultado de uma prótese imaginária, bem-vinda ou vinda por acaso, quase de bom senso." (VALAS, 2009) $)^{3}$

Alexander Stevens (1987), em seu artigo sobre a "holófrase”, considerou fazendo referência ao caso de Guir — a formação "Westminster — Winchester" como uma condensação e não como uma holófrase:

“Longe de discutir a pertinência dessas interpretações — do ponto de vista clínico - já que com efeito elas parecem ter o melhor efeito para a continuação da cura, não podemos considerar que se trata aqui da holófrase no sentido em que Lacan

\footnotetext{
${ }^{3}$ Disponível em: http://www.valas.fr/la-psychosomatique-un-fetiche-pour-les-ignorants,012.
} 
fala neste Seminário, já que as interpretações demonstram na cura o caráter de condensação singificante que têm os significantes em causa.” (STEVENS, 1987, p.66)

Para o autor, a holófrase é um monolito, em que a cadeia significante se encontra tomada em massa, ela não é enunciável em um significante particular, mas ela está situada na própria estrutura dos significantes em causa. O autor também fala de holófrase em relação aos fenômenos psicossomáticos, por exemplo, os enunciados alucinatórios.

\section{FENÔMENO PSICOSSOMÁTICO E OUTROS FENÔMENOS CLÍNICOS}

Paul Verhaeghe (2004) propõe uma versão original do termo de neurose atual sob a versão - generalizada — de patologia atual (actualpathology). Ele inclui aqui, fora das "neuroses atuais clássicas”, as somatizações psicossomáticas, o transtorno do pânico e a esquizofrenia com sua hipocondria inicial. Os estados-limite, a neurose traumática e a paranoia estariam no meio do caminho entre a patologia atual e a psicopatologia. Nesta última categoria (psychopathology), ele inclui as neuroses clássicas (a histeria e a obsessiva) e a parafrenia. Não obstante, ele precisa:

“A posição atual-patológica do sujeito pode parecer em todas as estruturas subjetivas, e todas as caraterísticas atual-patológicas vão ser completamente coloridas por esta estrutura. Na psicose, isto vai ser frequentemente a hipocondria, entendida como a preocupação ansiosa do sujeito com ‘algo' que em seu corpo não pode ser nomeado. Mais uma vez, na psicose, somos confrontados com as crises de angústia paroxísticas." (VERHAEGHE, 2004, p.307)

Ele considera que o argumento mais importante - para o diagnóstico da patologia atual — tem a ver com a presença de uma relação específica e característica entre o sujeito e o Outro. Esta relação se resume no fato de que o Outro fracassou na verbalização inicial do objeto a, tendo como resultado o fato de que a elaboração secundária não foi (ou foi logo depois) colocada em movimento.

Marcel Czermark (2007) falou dos fenômenos psicossomáticos em relação às respostas que observamos no real, quando um sujeito é interpelado do lugar onde ele não pode responder. Nós nos limitamos, neste artigo, a citar o catálogo de tais conjunturas de Czermak que — para além dos fenômenos psicossomáticos — repertoria também as seguintes conjunturas:

"A primeira: a maior, a mais massiva, a mais conhecida, a mais frequente é a angústia que responde no real. [...] sabemos bem que a angústia como tal, enquanto manifestação psicossomática, não é analisável. Pode-se analisar seus concomitantes, 
mas a angústia como tal não se presta à análise. A segunda: a alucinação. Igualmente uma resposta no real que não se presta à análise [...]. Terceira: os fenômenos de estrutura extremamente próximos da psicose e às vezes idênticas à psicose que são a passagem ao ato e mais lateralmente, o acting out, enfim a passagem ao ato essencialmente." (CZERMARK, 2007)

E ele lembra que antes de conceber seu conceito do Nome-do-Pai, Lacan havia falado de foraclusão (pensamos que ele se refere à famosa alucinação do homem dos lobos), o que é bem diferente da foraclusão do Nome-do-Pai. Do momento em que é tomado pela linguagem, Marcel Czermark diz:

"queiramos ou não, existem coisas que foram foracluídas para uns e outros e que serão inalcançáveis e que, ao serem solicitadas sobre este ponto, para sempre desaparecido, existem representantes sem representação e que também podem muito bem aparecer. Então, efetivamente, porque não os fenômenos das psicoses e das manifestações psicossomáticas, a angústia, etc." (CZERMARK, 2007) ${ }^{4}$

François Ansermet (1999, p.165) religa também, no contexto de uma hipótese linguageira ${ }^{5}$ de fenômenos psicossomáticos e de maneira bastante concordante com a hipótese de Joyce McDougal (1982) em relação ao "ato sintoma”, os fenômenos psicossomáticos à passagem ao ato:

"Na clínica do ato, gostaria de distinguir aqui o acting out da passagem ao ato. O acting out se endereça ao outro. É uma história sem falas. Seu surgimento pode ter um valor demonstrativo: o acting out demonstra o que não se pode dizer. O desencadeamento de uma conversão poderia ser considerado como sendo da ordem do acting out. Em contraposição ao acting out, na passagem ao ato a cena desaparece. Não há mais chamado. A passagem ao ato não se endereça a ninguém. Ela é mais o resultado de uma alienação, tentativa extrema de instauração subjetiva. Se a implusão suicida pode ser vista como o próprio modelo da passagem ao ato, o surgimento de um fenômeno psicossomático poderia ser compreendido como uma descarga pelo ato no corpo. Poder-se-ia inclusive aplicar também este modelo à crise bulímica e, de forma mais ampla, às condutas adutivas, colocando-os em série, como o fazem

\footnotetext{
${ }^{4}$ Disponível em: http://freud-lacan.com/freud/Champs_specialises/Presentation/A_propos_de_la_psychosomatique_4.

${ }^{5} \mathrm{O}$ autor distingue três tipos de hipóteses, avançadas pelos diferentes autores, quanto aos fenômenos psicossomáticos na criança: a hipótese linguageira, a hipótese pulsional (uma contaminação da necessidade pelo fato de estar implicada em outra satisfação) e a hipótese da relação com o ambiente, no sentido de uma falta de estimulação ou de um traumatismo.
} 
alguns autores: suicídio, crise bulímica, condutas adutivas e fenômenos psicossomáticos.” (ANSERMET, 1999, p.165)

O momento da passagem ao ato é, de acordo com Lacan (1962-1963/2004, p.136), "este do embaraço maior do sujeito, com a adição comportamental da emoção como desordem do movimento". Trata-se de momentos em que o sujeito é preso na armadilha do outro. Dora, lembra Lacan (1962-1963/2004, p.137), "passa ao ato no momento de embaraço em que é colocada a frase-armadilha, a armadilha desajeitada do Senhor K., Minha mulher não é nada para mim”. Será que poderíamos comparar os momentos parecidos a outros em que há "obrigação de resposta" e que poderia conduzir a manifestações clínicas como essas que Czermak e Ansermat, dentre outros autores, colocam em série, dentre os quais os fenômenos psicossomáticos?

\section{DISCUSSÃO}

Eis alguns pontos que merecem, em nossa opinião, ser discutidos em relação às divergências entre as teorias aqui expostas:

1. Como dissemos na introdução, há uma tendência em considerar os doentes que apresentam transtornos psicossomáticos como apresentando uma estrutura específica. A maior parte dos autores lacanianos não é favorável a esta emancipação estrutural dos casos que apresentam fenômenos psicossomáticos.

Porém, vimos que alguns autores lacanianos falam de uma relação específica desses sujeitos com o Outro, que vai no sentido de um “indecidível”. Nós nos perguntamos se este "indecidível” poderia favorecer a ocorrência de estados vivos de emoções e de embaraço nestes sujeitos. Estes últimos estados são, segundo Lacan, anunciadores e "coordenadores"6 da "passagem ao ato"; encontramos, então, talvez também por esta via, o parentesco dos fenômenos psicossomáticos com a "passagem ao ato".

2. Para Lacan e a maioria dos autores que se inspiram em Lacan, há uma diferença clara entre fenômenos psicossomáticos e conversão histérica, e até mesmo sintomas neuróticos no sentido geral. Esta diferenciação é menos clara, e até mesmo nula, em autores como Valabrega. Entretanto, os casos mistos de fenômenos somáticos complicados pelas conversões são bem conhecidos, através do conceito freudiano de complacência somática e isso não escapa à clínica lacaniana. Estes casos não são representativos dos fenômenos psicossomáticos: se uma histérica manifesta uma recusa de seu corpo (LACAN, 1969-1970/1991, p.107), seguindo o efeito do significante-mestre, ela não produz portanto um

\footnotetext{
${ }^{6}$ Ver quadro do seminário “A angústia” (LACAN, 1962-1963/2004, p.93).
} 
fenômeno psicossomático neste momento preciso. Porém, a frase de Lacan "o corpo se deixa escrever alguma coisa da ordem do número" e esta de Lebrun "o sujeito deixa a seu organismo o cuidado de resolver esta questão" deixam também entender uma complacência somática específica para os fenômenos psicossomáticos.

3. Quanto a tendência a concretizar a holófrase (isto é, considerá-la isolável em um aglomerado particular de palavras), vimos que não há acordo geral entre os autores lacanianos. Caso se considere a holófrase uma formação suscetível de ser desfragmentada, tocada por uma injunção significante, ou até mesmo interpretada, assimilaremos sensivelmente o fenômeno psicossomático a uma forma de condensação.

Mas existem poucos casos na literatura psicanalítica que mostram tais formações holofrásicas e esta raridade nos interroga sobre um possível forçamento da clínica em nome da teoria. Precipitar-se em deduzir a existência de tais formações, a partir do desaparecimento de fenômenos psicossomáticos pelas "injunções significantes", é um pouco audacioso, pois poderia tratar-se de efeitos de "sugestão" pela transferência. Inclusive, encontramos na literatura, casos de cura de fenômenos psicossomáticos pelo efeito da sugestão do mágico, do curador, do homeopata, etc.

Estamos de acordo com Valas (2009) quando ele avança que estas práticas permitem, por vários motivos, certa abertura ao outro, rompendo a autarquia que representa a lesão como manifestação de autoerotismo e que elas funcionam como um descondicionamento. Isto significa que talvez, nesses casos, o que conta é o estilo da intervenção do analista, mais do que o conteúdo de sua "interpretação". A revelação do gozo específico - que Lacan evoca em sua conferência em Genebra — não é provavelmente de tal "injunção", pois a frase de Lacan "revelar o sentido" não se refere à holófrase, mas ao gozo específico. Intervenções - do tipo injunção significante, desfragmentação, etc. — correm o risco de funcionar segundo o discurso do mestre e não segundo o discurso analítico. Entrentanto, tomemos nota desses casos anedóticos.

4. "Preservar" um fenômeno psicossomático - como uma suplência nos casos das psicoses - é uma pista que tentamos também explorar em outro trabalho (DIMITRIADIS, 2009), em relação à atimormia e ao humor delirante, considerados como fenômenos psicossomáticos, que atingiriam o cérebro dos pacientes psicóticos, "presos" pelos signos enigmáticos do Outro. Entretanto, o termo "preservar" poderia corresponder apenas a uma atitude não "ativa" do ponto de vista analítico, e não a um "deixar ir" (laisser aller) do fenômeno à deriva.

5. A colocação em paralelo dos fenômenos psicossomáticos clássicos com outros tipos de fenômenos clínicos, como a alucinação, alguns afetos (angústia, emoção, embaraço), a passagem ao ato e outros, têm bastante interesse, pois 
nos convida a pensar em um tipo de inscrição em curto-circuito com o Outro, em casos muito diferentes do ponto de vista das manifestações clínicas. E esta aproximação poderia ser instrutiva do ponto de vista estrutural, mas também útil quanto à direção da cura. Pois isso nos permitiria situar melhor os pontos sobre os quais ocorrem muitos fenômenos (entre os quais os chamados psicossomáticos), momentos talvez de emoção e/ou embaraço, seguido de uma obrigação de resposta, no lugar onde nenhuma resposta (no sentido de uma assunção pelas “representações”) ${ }^{7}$ não é possível ao sujeito, para além dos fenômenos de "apresentação do real”. Se essas apresentações de gênero podem se fazer de várias formas para os fenômenos psicossomáticos, mais especificamente, estas “apresentações” se fazem no real do corpo, fora da cena.

Recebido em 1/9/2013. Aprovado em 16/12/2013.

\section{REFERÊNCIAS}

ANSERMET, F. (1999) Modèles psychopathologiques du phénomène psychosomatique chez l'enfant. Neuropsychiatr Enfance Adolesc, v.47. n.3, p.161-168.

CZERMAK, M. (2007) “propos de la psychosomatique”. Séminaire de CZERMAK Marcel, Leçon du vendredi 1 juin 2007, in Association lacanienne internationale. Disponível em: www.freud-lacan.com.

DIMITRIADIS, G. (2009) Existe-t-il des affections psychosomatiques du cerveau?. Recherche en psychanalyse [on line], n.7. Psychanalyse, psychopathologie cognitive et neurosciences: quel débat? Disponível em: www.recherchespsychanalyse.revues.org/?

EDITORIAL. (1988) Le Trimestre psychanalytique, n.5. Sur la psychosomatique, Association Freudienne, p.XI-XII.

GUIR, J. (1984) Cancer et psychosomatique. Paris: Point hors ligne.

LACAN, J. LÉVY, R. DANON BOILEAU, H. (1953) Considérations psychosomatiques sur l'hypertension artérielle. L’Évolution psychiatrique, n.3, p.397-409.

LACAN, J. (1953-1954/1978) Le séminaire livre II, Le moi dans la théorie de Freud et dans la technique de la psychanalyse. Texte établi par Jacques-Alain Miller. Paris: Seuil.

LACAN, J. (1955-1956/1981) Le Séminaire livre III, Les psychoses. Texte établi par Jacques-Alain Miller. Paris: Seuil. . (1962-1963/2004) Le séminaire livre X, L’angoisse. Texte établi par Jacques-Alain Miller. Paris: Seuil.

\footnotetext{
${ }^{7}$ Ao risco de ser a extremada a exposição do acting-out.
} 
(1964/1973) Le Séminaire livre XI, Les quatre concepts fondamentaux de la psychanalyse. Texte établit par Jacques-Alain Miller. Paris: Seuil. (1969-1970/1991) Le Séminaire livre XVII, L'envers de la psychanalyse. Texte établi par Jacques-Alain Miller, Paris: Seuil, mars 1991.

. (1973) Télévision. Paris: Seuil.

(1974-1975) Le Séminaire, Livre XXII, RSI, séance du 21 janvier 1975, inédit.

(1975), Conférence à Genève sur "Le symptôme". Le bloc-notes de la psychanalyse, n.5, p.5-23.

LEBRUN, J. (2006) “Le corps affecté: propos de Mars de Fritz Zorn”, in MICHELS, A. \& LANDMAN, P.(dir.). Les limites du corps, le corps comme limite. Paris: érès, p.155-172.

LIART, M. (1989) Le P.P.S. comme suppléance dans la psychose. Quarto, n. $37 / 38$, p. 87 .

(1992) La jouissance spécifique du phénomène psychosomatique”. Quarto, n.50, p.15-19.

MARTY, P.(1990) La psychosomatique de l'adulte. Paris: PUF (coll. Que sais-je n.1850).

MCDOUGALL, J. (1982) Théâtre du je. Paris: Gallimard (coll. Folio essais).

MELMAN, C.(1988) propos de quatre cas de Torticolis spasmodique. Le Trimestre psychanalytique, n.5, Sur la psychosomatique, Association Freudienne, p.101-108.

MILLER, J.-A. (1986) "Quelques réflexions sur les phénomènes psychosomatiques”, in Les phénomènes psychosomatiques et la psychanalyse. Paris: Navarin, p.113-126 (coll. Analytica n.48).

MONRIBOT, P.(2007) Qu'est-ce que la psychosomatique? Aperçus psychanalytiques Disponível em: http://psychanalyse67.com/Documents/Montribot\%20Psychosomatique.pdf.

NICOLAIDIS, N. (1993) La force perceptive de la représentation de la pulsion. Paris: PUF.

PEDINIELLI, J.-L., ROUAN, G. (1998) Concept d'alexithymie et son intérêt en psychosomatique. Encyclopédie Médico-Chirurgicale, Psychiatrie, 37-400-D-20, p.1-6.

STEVENS, A. (1987) L'holophrase, entre psychose et psychosomatique. Ornicar, n.42, p.64-71.

VALABREGA, J.-P. (1954) Les théories psychosomatiques. Paris: PUF. (1966) Problèmes de théories psychosomatiques, Encyclopédie Médico-Chirurgicale, Psychiatrie, 37400 C 10.

VALAS, P.(2009) La psychosomatique: un fétiche pour les ignorants, in Patrick Valas. Disponível em: www.valas.fr

VERHAEGHE, P.(2004) On being normal and other disorders. New York: Other Press.

Yorgos Dimitriadis

dimitriadisyorgos@gmail.com

Fabiana Campos Baptista

fabibap77@hotmail.com 
